\title{
Fluorescence Immunohistochemistry by Confocal Laser-Scanning Microscopy for Studies of Semi-Ultrathin Specimens of Epoxy Resin-Embedded Samples
}

\author{
Shin-ichi Iwasaki and Hidekazu Aoyagi \\ The Nippon Dental University School of Life Dentistry at Niigata \\ ctpan
}

\section{Introduction}

It is difficult to visualize histological details on semi-ultrathin sections by light microscopy after immunohistochemical labeling because the histological structures in such sections cannot be distinguished by standard counter-staining. To solve this problem and to visualize the immunoreactivity specific for various antigens, we have developed a technique that involves a combination of immunofluorescent staining of semi-ultrathin sections of epoxy resin-embedded samples and either the corresponding differential interference contrast (DIC) images or the corresponding images in transmission mode obtained by confocal laser-scanning microscopy (LSM), providing detailed information about the immuno-localization of histological and cellular structures.

Haraguchi and Yokota (2002) were the first to describe a similar method, including treatment of sections with 10\% sodium ethoxide to remove epoxy resin (Litwin et al., 1984) and reaction with fluorescence-labeled second antibodies. In our method, we use $10 \%$ sodium methoxide to remove epoxy resin from sections (Mayor et al., 1961). There is no significant difference between the two treatments, but Haraguchi \& Yokota (2002) used fluorescence-labeled second antibodies while we use a combination of biotin-conjugated second antibodies and streptavidin fluorescence. Our preliminary experiments indicated that the latter system has greater sensitivity than the former in the case of semi-ultrathin sections. Using our above-mentioned method, we are now easily able to detect immunofluorescence on semi-ultrathin sections of epoxy resin-embedded specimens.

To demonstrate the effectiveness of our method, in the present study we examined the immunofluorescence of immuno-stained keratins and collagens and the images obtained, in transmission mode, of the lingual mucosa of the filiform and circumvallate papillary areas of tongues of fetus and juvenile rats by LSM. By combining images, we were able to define clearly the histological locations of keratin 13 (K13) and keratin 14 (K14) in the lingual epithelium (Iwasaki et al., 2006a, 2011a) and those of collagen II (CII) and collagen III (CIII) in the lingual connective tissue (Asami et al., 2008, Iw asaki et al., 2008, 2011b). Furthermore, we demonstrated that our newly developed technique for localization of pairs of antigens should be useful for investigations of very small specimens, such as fetal tissues and organs (Aoyagi et al., 2008). 


\section{Experimental methods}

\subsection{Experimental animals}

Sprague-Dawley (SPF) rats were used for all observations. Tongues were removed from fetal and juvenile rats after they had been killed by an intraperitoneal overdose of sodium pentobarbital.

\subsection{Preparation of tissue}

Rat lingual tissues were fixed in $4 \%$ formaldehyde titrated from paraformaldehyde (Table 1A) in $0.1 \mathrm{M}$ phosphate buffer (PBS; pH 7.4; Table 1-B) at $4{ }^{\circ} \mathrm{C}$ for $5 \mathrm{~h}$. After rinsing in $0.1 \mathrm{M}$ PBS, all samples were transferred to an ascending ethanol series $(60 \%, 70 \%, 80 \%, 90 \%$ and 99\% ethanol; $10 \mathrm{~min}$ each) and then to absolute ethanol (twice for $15 \mathrm{~min}$ each) for dehydration. After immersion in propylene oxide (twice for $15 \mathrm{~min}$ each), each specimen was transferred to a mixture of propylene oxide and epoxy resin (1:1, v/ v), and embedded in epoxy resin (Table 1-C), which was allowed to polymerize overnight at $60{ }^{\circ} \mathrm{C}$. Then the epoxy resin-embedded blocks were sectioned at 500-nm thickness with a diamond knife on an ultramicrotome (MT-XL; RMC, Tucson, AZ, USA). The resultant semi-ultrathin sections were mounted on glass slides (Matsunami Glass Inc., Osaka, Japan) and incubated in 10\% sodium methoxide (Table 1-D) for $2 \mathrm{~min}$ at room temperature to remove the epoxy resin (Mayor et al., 1961). After passage through an acetone series, which consisted of absolute acetone (two times) and 50\% acetone (once), sections were transferred to PBS (pH 7.4). Each specimen was passed rapidly through each solvent, that is to say, with immersion for $30 \mathrm{sec}$ or so.

\subsection{Immunofluorescence staining}

After retrieval of antigens (Shi et al., 1991) by heating in a microwave oven at $500 \mathrm{Watts}$ for 2 min in $10 \mathrm{mM}$ sodium citrate buffer ( $\mathrm{pH}$ 6.0; Table 1-E), sections on slides were allowed to cool for $8 \mathrm{~min}$ and were then transferred to $\mathrm{PBS}$ ( $\mathrm{pH}$ 7.4) at room temperature. Sections were then incubated with primary antibodies overnight at $4{ }^{\circ} \mathrm{C}$. The primary antibodies that we used in this study are shown in Table 2. To determine the optimum working dilutions of each preparation of antibodies, we tested dilutions from 1:25 to 1:800. After washing in PBS, sections were incubated with biotin-conjugated antibodies raised in rabbit against mouse IgG, IgA and IgM (Nichirei Biosciences, Tokyo, Japan) or with biotin-conjugated antibodies raised in goat against rabbit IgG (Nichirei Biosciences) for $30 \mathrm{~min}$ at room temperature. Secondary antibodies are also shown in Table 2. Sections were incubated with streptavidinAlexa Fluor 488 or 633 (Molecular Probes, Eugene, OR, USA) for $30 \mathrm{~min}$ at room temperature. Fluorescent reagents are shown in Table 3. Sections were then mounted with FluoroGuard ${ }^{\mathrm{TM}}$ antifade reagent (Bio-Rad Laboratories, Hercules, CA, USA) after washing in PBS. Each specimen was covered with a glass coverslip (Matsunami Glass Inc) with clear nail varnish as adhesive. The main steps for immunofluorescence staining are summarized in Table4. The specificity of immunoreactions was checked by preparation of the following controls: a control without primary antibodies; a control incubated with normal mouse serum instead of primary antibodies; and controls incubated with antibodies that had been incubated for $24 \mathrm{~h}$ at $4{ }^{\circ} \mathrm{C}$ with the corresponding antigen at 10 to $100 \mu \mathrm{g} / \mathrm{ml}$. No immunolabeling of the lingual mucosa of fetal and juvenile rats was seen in any of the negative controls. 


\begin{tabular}{|c|c|c|}
\hline & Reagent & Preparation \\
\hline A & $\begin{array}{l}4 \% \text { formaldehyde } \\
\text { titrated from } \\
\text { paraformaldehyde }\end{array}$ & $\begin{array}{l}\text { (1) } 25 \mathrm{ml} \text { of distilled water (DW) are heated almost to boiling } \\
\text { point. } \\
\text { (2) } 2 \mathrm{~g} \text { of paraformaldehyde (fine granules; TAAB) are added to } \\
\text { the hot DW and are dissolved by gentle shaking. } \\
\text { (3) Upon addition of one to three drops of } 1 \mathrm{~N} \mathrm{NaOH} \text {, the } 2 \mathrm{~g} \text { of } \\
\text { paraformaldehyde are completely dissolved in } \mathrm{DW} \text {. } \\
\text { (4) Finally, a small amount of } \mathrm{DW} \text { is added to give bring the total } \\
\text { volume back to } 25 \mathrm{ml} \text {. } \\
\text { (5) Phosphate-buffered saline (PBS) is prepared as a } 10 \mathrm{x} \text { stock } \\
\text { solution that contains } 1.37 \mathrm{M} \mathrm{NaCl}, 27 \mathrm{mM} \mathrm{KCl}, 100 \mathrm{mM} \\
\mathrm{Na}_{2} \mathrm{HPO} \text { and } 18 \mathrm{mM} \mathrm{KH}_{2} \mathrm{PO}_{4} \text { (adjusted to pH } 7.4 \text { with } \mathrm{HCl} \text {, if } \\
\text { necessary) and is stored at } 4{ }^{\circ} \mathrm{C} \text {. } \\
\text { (6) A working solution is prepared by dilution of one part stock } \\
\text { solution with four parts distilled and deionized water (DDW). } \\
\text { (7) Mix } 25 \text { ml of the solution of paraformaldehyde with } 25 \mathrm{ml} \text { of } \\
\text { 2x PBSjust before use. }\end{array}$ \\
\hline B & $\begin{array}{l}0.1 \mathrm{M} \text { phosphate } \\
\text { buffer (pH 7.4) }\end{array}$ & $\begin{array}{l}\text { (1) Prepare a } 10 \mathrm{x} \text { stock solution of } \mathrm{PBS} \text { with } 1.37 \mathrm{M} \mathrm{NaCl}, 27 \mathrm{mM} \\
\mathrm{KCl}, 100 \mathrm{mM} \mathrm{Na} \mathrm{HPO}_{4} \text { and } 18 \mathrm{mM} \mathrm{KH}_{2} \mathrm{PO}_{4} \text { (adjust to } \mathrm{pH} 7.4 \\
\text { with } \mathrm{HCl} \text {, if necessary) and store at } 4{ }^{\circ} \mathrm{C} \text {. } \\
\text { (2) Prepare a working solution by dilution of one part stock } \\
\text { solution with nine parts DDW. }\end{array}$ \\
\hline $\mathrm{C}$ & Epoxy resin & $\begin{array}{l}\text { (1) Solution A: } 62 \mathrm{ml} \text { of Epon } 812 \text { and } 100 \mathrm{ml} \text { of dodecenyl } \\
\text { succinic anhydride (DDSA; TAAB). } \\
\text { (2) Solution B: } 100 \mathrm{ml} \text { of Epon } 812 \text { and } 89 \mathrm{ml} \text { of methyl nadic } \\
\text { anhydride (MNA). } \\
\text { (3) Mix equal volumes of solutions A and B, adding } 1.5 \text { to } 1.8 \% \\
\text { tri-dimethylaminomethyl phenol (DMP-30; TAAB) for } \\
\text { polymerization. }\end{array}$ \\
\hline $\mathrm{D}$ & $\begin{array}{l}10 \% \text { sodium } \\
\text { methoxide }\end{array}$ & $\begin{array}{l}\text { (1) Add } 20 \mathrm{~g} \text { of sodium metal to } 200 \mathrm{ml} \text { of absolute methanol in a } \\
1,000 \text {-ml flask; bubbling will occur for approximately } 20 \text { min. } \\
\text { (2) Add methanol to give a volume of } 200 \mathrm{ml} \text {, to compensate for } \\
\text { losses due to evaporation. } \\
\text { (3) After addition of } 200 \mathrm{ml} \text { of benzene, add } 50 \text { to } 100 \mathrm{ml} \text { of } \\
\text { methanol until complete fusion of methanol and benzene has } \\
\text { occurred. }\end{array}$ \\
\hline $\mathrm{E}$ & $\begin{array}{l}10 \mathrm{mM} \text { sodium } \\
\text { citrate buffer }(\mathrm{pH} \\
6.0)\end{array}$ & $\begin{array}{l}\text { (1) } 10 \mathrm{mM} \text { sodium citrate buffer (pH 6.0): prepare a } 20 \mathrm{x} \text { stock } \\
\text { solution with } 20 \mathrm{ml} \text { of } 200 \mathrm{mM} \text { citric acid and } 80 \mathrm{ml} \text { of } 200 \mathrm{mM} \\
\text { sodium citrate. } \\
\text { (2) Prepare the working solution by dilution of one part stock } \\
\text { solution with nineteen parts DDW. }\end{array}$ \\
\hline
\end{tabular}

Table 1. Preparation of reagents for fixation of tissues and immunofluorescence staining. 


\begin{tabular}{|l|l|l|l|l|l|}
\hline Antibodies & Origin & Host & Type & Dilution & Company \\
\hline Anti-K13 & Human & Mouse & Monoclonal & $1: 50-1: 100$ & $\begin{array}{l}\text { Progen Biotech GmbH, } \\
\text { Germany }\end{array}$ \\
\hline Anti-K14 & Human & Mouse & Monoclonal & $1: 50-1: 100$ & $\begin{array}{l}\text { Cymbus Bioscience Ltd., } \\
\text { UK }\end{array}$ \\
\hline Anti-CII & Rat & Rabbit & Polyclonal & $1: 50-1: 100$ & $\begin{array}{l}\text { Chemicon International, } \\
\text { Inc., USA }\end{array}$ \\
\hline Anti-CIII & Rat & Rabbit & Polyclonal & $1: 50-1: 100$ & $\begin{array}{l}\text { Chemicon International, } \\
\text { Inc., USA }\end{array}$ \\
\hline $\begin{array}{l}\text { Biotin-conjugated } \\
\text { anti-mouse }\end{array}$ & --- & Rabbit & --- & $10 \mu \mathrm{g} / \mathrm{ml}$ & $\begin{array}{l}\text { Nichirei Biosciences, } \\
\text { Japan }\end{array}$ \\
\hline $\begin{array}{l}\text { Biotin-conjugated } \\
\text { anti-rabbit }\end{array}$ & --- & Goat & -- & $10 \mu \mathrm{g} / \mathrm{ml}$ & $\begin{array}{l}\text { Nichirei Biosciences, } \\
\text { Japan }\end{array}$ \\
\hline
\end{tabular}

Table 2. Primary and secondary antibodies used in this study.

\begin{tabular}{|l|l|l|}
\hline Label & Dilution & Company \\
\hline Streptavidin-Alexa Fluor 488 & $10 \mu \mathrm{g} / \mathrm{ml}$ & Molecular Probes, USA \\
\hline Streptavidin-Alexa Fluor 633 & $10 \mu \mathrm{g} / \mathrm{ml}$ & Molecular Probes, USA \\
\hline
\end{tabular}

Table 3. Fluorescent reagents used in this study.

\begin{tabular}{|c|l|}
\hline Step & \multicolumn{1}{|c|}{ Procedure } \\
\hline 1 & $\begin{array}{l}\text { Retrieval of antigens by heating in a microwave oven }(500 \mathrm{~W} \text { ) for } 2 \mathrm{~min} \text { in } 10 \mathrm{mM} \\
\text { sodium citrate buffer }(\mathrm{pH} 6.0)\end{array}$ \\
\hline 2 & Cooling for 8 min at room temperature \\
\hline 3 & Incubation with the primary monoclonal or polyclonal antibodies overnight at $4^{\circ} \mathrm{C}$ \\
\hline 4 & Washing in PBS \\
\hline 5 & $\begin{array}{l}\text { Incubation with biotin-conjugated rabbit antibodies against mouse IgG, IgA and } \\
\text { ggM or with biotin-conjugated goat antibodies against rabbit IgG for } 30 \text { min at } \\
\text { room temperature }\end{array}$ \\
\hline 6 & Washing in PBS \\
\hline 7 & $\begin{array}{l}\text { Incubation with streptavidin-Alexa Fluor } 448 \text { or } 633 \text { for } 30 \text { min at room } \\
\text { temperature }\end{array}$ \\
\hline 8 & Mounting with FluoroGuardTM antifade reagent \\
\hline
\end{tabular}

Table 4. A summary of methods, showing the main steps for immunofluorescence staining.

Using our new technique, we were able easily to detect and localize immunofluorescence in the tongues of fetal and juvenile rats. In the present study, we used DIC images and images in transmission mode obtained by LSM to examine the same specimens as those in which we monitored the fluorescence of Alexa Fluor 488 or 633 . We were able to define the histological location of K13, K14, CII and CIII by combining the respective images. 


\subsection{Confocal laser-scanning microscopy (LSM)}

All specimens were examined with a confocal laser-scanning microscope (LSM510 or LSM710; Carl Zeiss, Jena, Germany) that was equipped with an argon laser or a heliumneon $(\mathrm{HeNe})$ laser. The dimensions of all images displayed on the monitor were $1024 \times 1024$ pixels. For single scanning for detection of the fluorescence of Alexa Fluor 488 (Molecular Probes), we used a 488-nm laser wavelength filter; a 488-nm primary dichroic beam-splitter; and a 505- to 530-nm band-pass filter. These specimens were examined with a confocal laserscanning microscope that was fitted with an argon laser. For single scanning for detection of the fluorescence of Alexa Fluor 633, we used a 633-nm laser wavelength filter; a 514/633-nm primary dichroic beam-splitter; and a 650-nm low-pass filter. These specimens were examined with a confocal laser-scanning microscope that was fitted with a HeNe laser. Combinations of pixel sizes from $0.12 \mu \mathrm{m} \times 0.12 \mu \mathrm{m}$ to $0.17 \mu \mathrm{m} \times 0.17 \mu \mathrm{m}$ and a $40 \mathrm{x}$ objective with a numerical aperture (NA) of 0.75 were used for observations. We also examined DIC images that revealed the histology and morphology of cells on the same semi-ultrathin sections. We stacked the immunofluorescence images and the corresponding DIC images by computer, as summarized in Table 5. Furthermore, after staining of specimens with $0.2 \%$ toluidine blue (Waldeck $\mathrm{GmbH} \& \mathrm{Co}$., Münster, Germany) in 2.5\% $\mathrm{Na}_{2} \mathrm{CO}_{3}$, we examined the corresponding images by LSM in the transmission mode. Finally, two images, showing the immunoreactivity of a specific antigen and the histology, recorded in transmission mode, were stacked on top of one another, by computer, for analysis.

\begin{tabular}{|c|l|}
\hline Step & \multicolumn{1}{|c|}{ Procedure } \\
\hline $1^{*}$ & Fluorescent immunostaining \\
\hline $2^{*}$ & Immunofluorescent images obtained by LSM \\
\hline 3 & DIC images obtained by LSM \\
\hline 4 & Toluidine blue staining \\
\hline 5 & Images in transmission mode obtained by LSM \\
\hline 6 & Combination of immunofluorescent and DIC images \\
\hline 7 & Combination of immunofluorescent and transmission-mode images \\
\hline
\end{tabular}

Table 5. A summary of methods for the stacking of images of immunoreactivity and DIC images or images obtained by LSM in transmission mode.

* Steps 1 and 2 should be repeated using adjacent semi-ultrathin sections and antibodies with two different specificities to show the localization of pairs of antigens.

To reveal the combined localization of the pair of antigens of K13 and of K14, we stacked three images obtained by LSM, which showed the immunoreactivity of each antigen and the histology, recorded in transmission mode, on top of one another by computer and analyzed the results after examining the same respective DIC images and images obtained in transmission mode.

\section{Experimental results and analyses}

\subsection{Localization of immunofluorescence specific for K13 and K14 in the lingual epithelium during morphogenesis of non-gustatory papillae}

We have not yet succeeded in the double immunolabeling of samples prepared by the epoxy-resin method. Therefore, instead of double immunolabeling, we immunolabeled K13 
and $\mathrm{K} 14$, separately, in adjacent sections. We then stacked the two resultant images together with an image obtained by LSM, in transmission mode, using a computer (Aoyagi et al., 2008). The combination of laser-scanning micrographs, which show the immunolabeling of $\mathrm{K} 13$ and K14 in the fetal rat tongue, and images obtained by LSM in transmission mode is shown in Figure 1.

Localization of immunofluorescence specific for K13 and K14 in the lingual epithelium during morphogenesis of non-gustatory papillae, as revealed by the above-mentioned double immunolabeling, is shown in Figure 2. Filiform papillae, which are non-gustatory lingual papillae, were compactly distributed on the dorsal surface of the lingual body of rats after birth, and these papillae developed rapidly just before birth (Iwasaki et al., 1997). Morphogenesis of filiform papillae is closely related to the keratinization of the dorsal lingual epithelium (Iwasaki et al., 1999). Immunoreactivity specific for K13 and for K14 was not detected on the lingual epithelium of fetuses on day 15 after conception (E15), at which time the lingual epithelium was composed of a few layers of cuboidal cells. Immunoreactivity specific for K13 and K14 was distinct at all postnatal stages examined. Although the respective patterns of K13-specific and K14-specific immunoreactivity differed as the filiform papillae developed, immunoreactivity specific for K13 was generally evident in the suprabasal cells of the interpapillary cell columns, where keratinization was weaker than in the papillary cell columns. Immunoreactivity specific for K14 was detected in the basal and suprabasal cells, which were mitotically active, of the papillary and interpapillary cell columns. Immunoreactivity specific for $\mathrm{K} 13$ in immunopositive cells in the interpapillary cell columns was densely distributed in the cytoplasm exclusively and non was evident in the nuclei. The same was true of the immunoreactivity specific for K14. Furthermore, immunoreactivity specific for K13 in the suprabasal cells of the interpapillary cell columns was more densely distributed than it was in the suprabasal cells of the papillary cell columns. By contrast, immunoreactivity specific for K14 in the basal and suprabasal cells of the papillary cell columns was more distinctively distributed than it was in the interpapillary cell columns. The corresponding images in transmission mode clearly revealed that the lingual epithelium was composed of stratified squamous cells and, in addition, that rounded rudiments of filiform papillae were arranged at equal intervals, for the most part, just before and just after birth. The sizes of basal cells in the papillar and interpapillar regions were almost same as those of cells in the dorsal epithelium of the tongue. At this stage, the connective tissue was beginning to penetrate into the central part of each filiform papilla and, as a result, the epithelial-connective tissue border was undulated (Iw asaki et al., 2006a).

\subsection{Localization of immunofluorescence specific for K13 and K14 in the lingual epithelium during the morphogenesis of gustatory papillae}

Localization of immunofluorescence specific for K13 and K14 in the epithelium during the morphogenesis of circumvallate papillae, which are gustatory papillae, in fetal and juvenile Sprague-Dawley rats is shown in Figures 3, 4 and 5. Only a single circumvallate papilla, one type of gustatory lingual papilla, is located medially on the dorsal surface at the end of the lingual body (Iwasaki et al., 1997). We used fluorescence immunohistochemistry, analysis of DIC images and LSM in the transmission mode, after staining specimens with toluidine blue, to examine the localization of $\mathrm{K} 13$ and K14 in the lingual epithelium of rats during the prenatal and postnatal morphogenesis of the circumvallate papillae. No immunoreactivity 

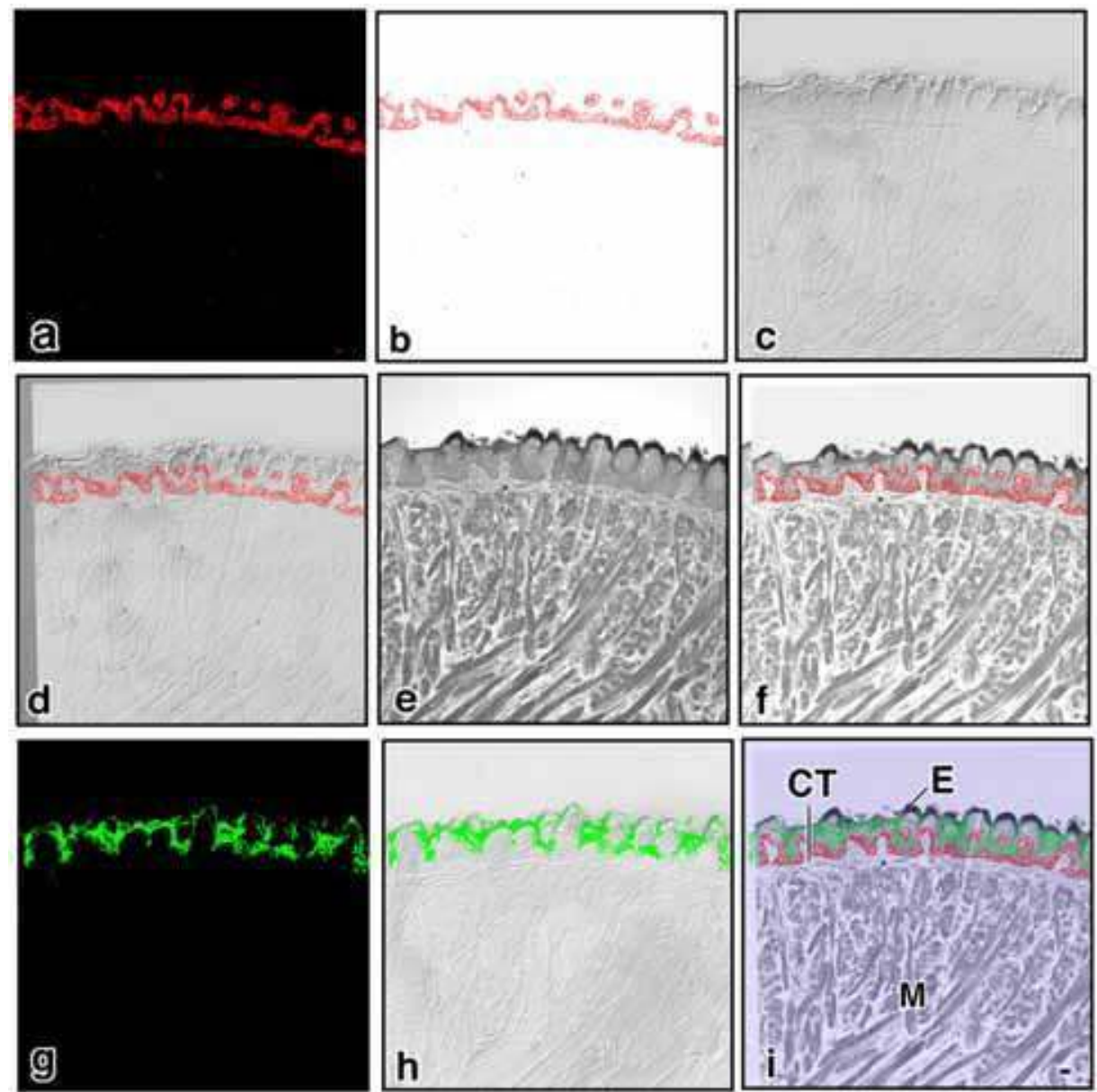

Fig. 1. The stacking of images of immunofluorescence with DIC images and with images obtained by LSM in transmission mode. Micrographs of two sagittally adjacent sections on P0, which show the immunolabeling of K13 (Alexa Fluor 633; green) and of K14 (Alexa Fluor 488; red) in the lingual epithelium of rats on P0 and the images obtained by LSM in the transmission mode, are stacked as follows.

(a) Immunofluorescence of K14 obtained by LSM;

(b) removal of the background from image in (a);

(c) DIC image of the same section as in (a), obtained by LSM;

(d) stacking of images in (b) and (c);

(e) image obtained by LSM in transmission mode after toluidine blue staining;

(f) stacking of images in (b) and (e);

(g) immunofluorescence of K14 obtained by LSM;

(h) stacking of image in (g), without background, and in (c); and

(i) stacking of images in (b), in (g) without background, and in (e).

E, Dorsal lingual epithelium; CT, connective tissue; and M, muscle. Bars $=10 \mu \mathrm{m}$. 

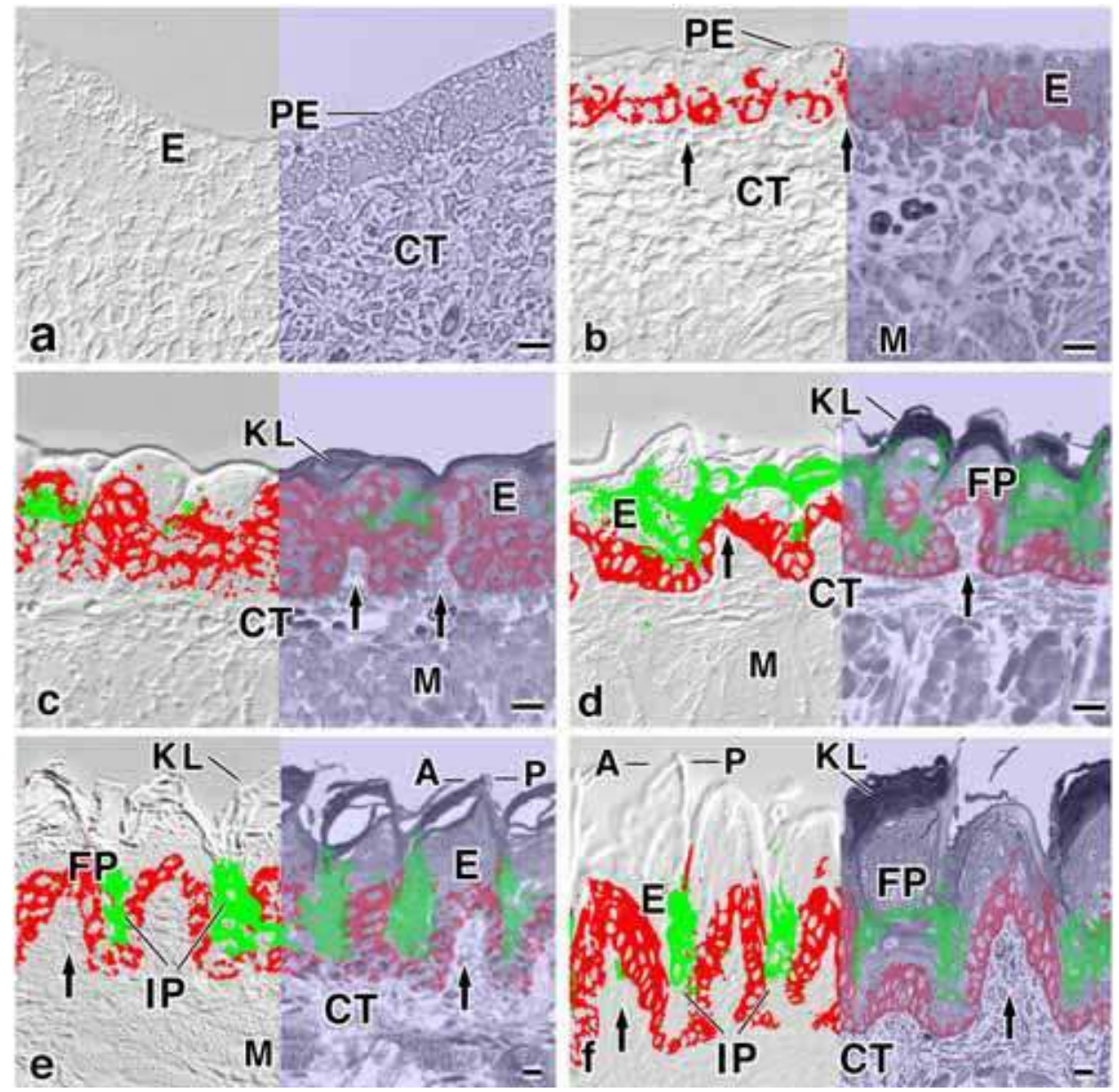

Fig. 2. Combination of laser-scanning micrographs, which show the immunolabeling of K13 (Alexa Fluor 633; green) and of K14 (Alexa Fluor 488; red) in the fetal rat tongue, and DIC images (left half of each micrograph) or images obtained by LSM in transmission mode (right half of each micrograph) that show the histology and cellular morphology of semiultrathin sections.
(a) Sagittal section from a fetus on E15;
(b) sagittal section from a fetus on E17;
(c) sagittal section from a fetus on E19;
(d) sagittal section from a juvenile on $\mathrm{P} 0$;
(e) sagittal section from a juvenile on $\mathrm{P} 7$; and
(f) sagittal section from a juvenile on P14.

E, Dorsal lingual epithelium; PE, periderm; CT, connective tissue; FP, filiform papillae; KL, keratinized cell layer; M, muscle; IP, interpapillary cell column; A, anterior cell column of filiform papilla; $\mathrm{P}$, posterior cell column of filiform papilla; and arrows, connective tissue papillae. Bars $=10 \mu \mathrm{m}$. 


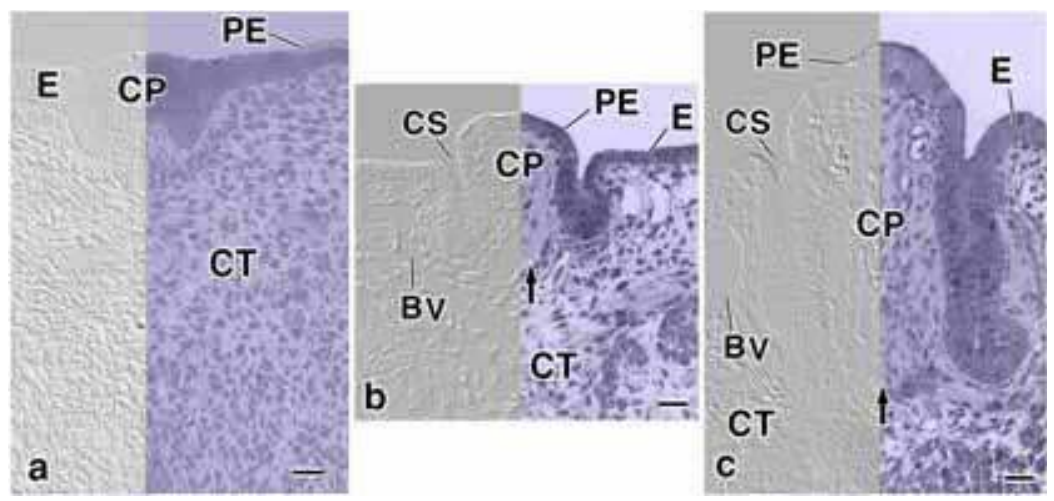

Fig. 3. Combination of laser-scanning micrographs, which show the immunolabeling of K13 in the fetal rat tongue, and DIC images (left half of each micrograph) or images obtained by LSM in transmission mode (right half of each micrograph) that show the histology and cellular morphology of semi-ultrathin sections. No immunoreactivity was recognizable.

(a) Transverse section from a fetus on E15;

(b) transverse section from a fetus on E17; and

(c) transverse section from a fetus on E19.

E, Dorsal lingual epithelium; PE, periderm; CT, connective tissue; CP, circumvallate papilla; $\mathrm{CS}$, circular sulcus; M, muscle; BV, blood vessel; and arrows, connective tissue papillae. Bars $=20 \mu \mathrm{m}$.

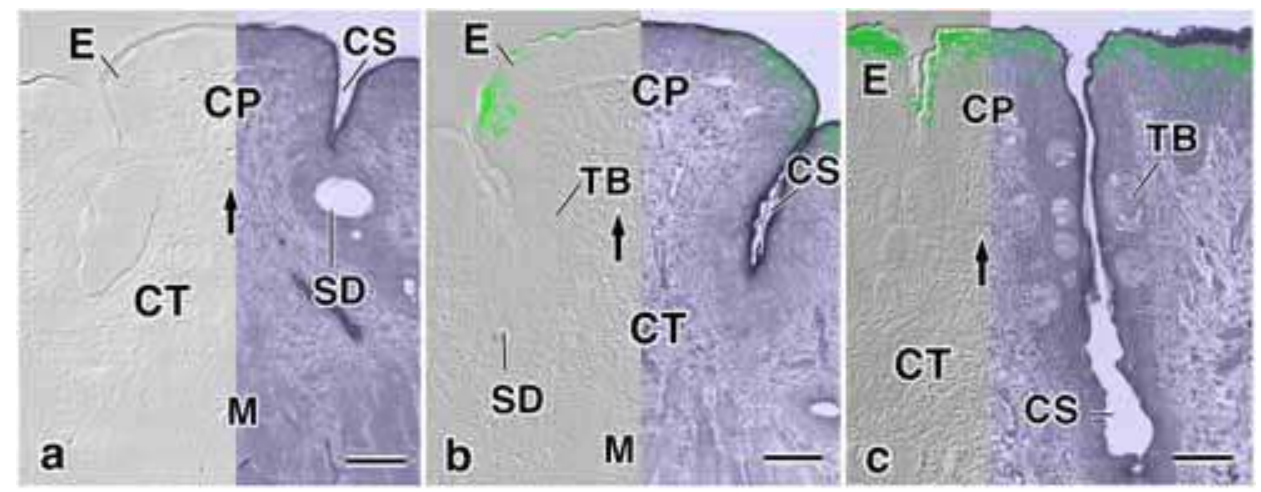

Fig. 4. Combination of laser-scanning micrographs, which show the immunolabeling of K13 (Alexa Fluor 633; green) in the juvenile rat tongue, and DIC images (left half of each micrograph) or images obtained by LSM in transmission mode (right half of each micrograph) that show the histology and cellular morphology of semi-ultrathin sections.

(a) Transverse section from a juvenile on $\mathrm{P0}$;

(b) transverse section from a juvenile on P7; and

(c) transverse section from a juvenile on P14.

E, Dorsal lingual epithelium; CT, connective tissue; CP, circumvallate papilla; CS, circular sulcus; M, muscle; TB, taste bud; SD, secretory duct of von Ebner's gland; and arrows, connective tissue papillae. Bars $=50 \mu \mathrm{m}$. 


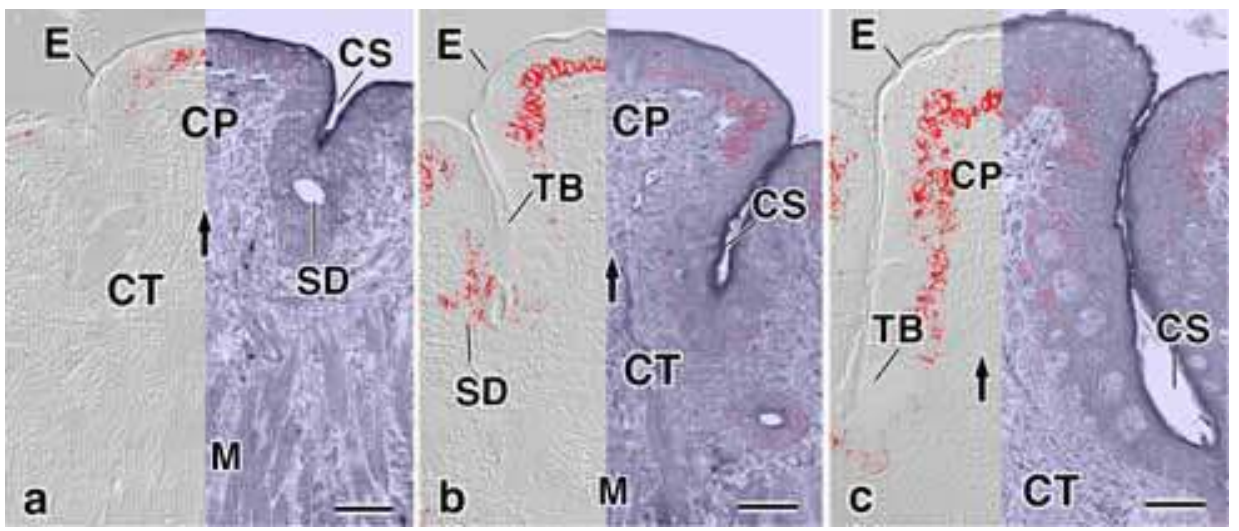

Fig. 5. Combination of laser-scanning micrographs, which show the immunolabeling of K14 (Alexa Fluor 488; red) in the juvenile rat tongue, and DIC images (left half of each micrograph) or images obtained by LSM in transmission mode (right half of each micrograph) that show the histology and cellular morphology of semi-ultrathin sections.

(a) Transverse section from a juvenile on $\mathrm{P} 0$;

(b) transverse section from a juvenile on P7; and

(c) transverse section from a juvenile on P14.

E, Dorsal lingual epithelium; CT, connective tissue; CP, circumvallate papilla; CS, circular sulcus; M, muscle; TB, taste bud; SD, secretory duct of von Ebner's gland; and arrows, connective tissue papillae. Bars $=50 \mu \mathrm{m}$.

specific for K13 and K14 was detected in the lingual epithelium of fetuses on E15, at which time the circumvallate papillary placode, the primitive rudiment of the circumvallate papilla, was detectable as the thickening of several layers of cuboidal epithelial cells. On E17 and E19, the developing circumvallate papillae were clearly recognizable, each onsisting of a central papilla and the surrounding sulcus. No immunoreactivity specific for K13 and K14 was evident in the lingual epithelium around these structures at this time. K14-specific immunoreactivity was first detected in the basal layer of the epithelium of the circumvallate papillae on P0 (the day of birth) and K13-specific immunoreactivity was detected on P7. Morphogenesis of the circumvallate papillae progressed significantly from P0 to P14, and immunoreactivity specific for K13 and K14 was clearly recognizable after P7. The respective patterns of K13-specific and K14-specific immunoreactivity differed during the development of the circumvallate papillae. K13-specific immunoreactivity was generally evident in cells in the intermediate layer of the epithelium, while K14-specific immunoreactivity was detected in cells in the basal and suprabasal layers.

The immunostaining method used in the present study, with removal of epoxy-resin and antigen retrieval by microwaving, was fundamentally the same as that used in previous studies (Aoyagi et al., 2008; Asami et al., 2008; Iwasaki et al., 2008). Therefore, the observed significant differences between the respective patterns of distribution of immunoreactive $\mathrm{K} 13$ and K14 in filiform papillary regions and circumvallate papillary regions are unlikely to be based on differences in methodology. The main reason for the differences in the respective patterns of distribution of K13 and K14 between the two areas might be the differences in the patterns of stratification and keratinization of the epithelium between the two areas. In particular, the difference in the timing of the appearance of K14 seems to be 
related to the difference in the timing of initiation of the stratification of the epithelium. It is possible that the appearance of K14 in basal cells of the lingual epithelium might induce changes in the lingual dorsal epithelium, namely, morphogenesis of filiform papillae, keratinization of the epithelium of the papillary cell column, and so on (Aoyagi et al., 2008). The initiation of stratification in the filiform papillary area clearly occurs earlier than that in the circumvallate papillary area, and K14-specific immunoreactivity in the filiform papillary area appears earlier than that in the circumvallate papillary area. By contrast, the appearance of K13-specific immunoreactivity seems to be related both to the stratification and to the keratinization of the epithelium. As indicated by Aoyagi et al. (2008), K13 is widely distributed in the suprabasal layer of the entire lingual epithelium before the initiation of the hard keratinization of the filiform papillae. However, the region of which K13 appears is restricted to the suprabasal and intermediate layers of the interpapillary cell columns, in which hard keratinization does not develop. After P7, K13-specific immunoreactivity was evident on the surface and upper intermediate layers of the epithelium in the circumvallate papillary area, but no hard keratinization was evident in this region. Thus, the pattern of keratinization of the epithelium clearly differs between the filiform papillary area and the circumvallate papillary area (Iw asaki et al., 2011a).

\subsection{Localization of immunofluorescence specific for $\mathrm{Cll}$ and $\mathrm{CIII}$ in the lingual mucosa during morphogenesis of non-gustatory papillae}

Localization of immunofluorescence specific for CII and CIII in the connective tissue of the mucosa during morphogenesis of the circumvallate papillae, which are gustatory papillae, of fetal and juvenile rats is shown in Figures 6 and 7.

As shown in Figure 6, immunoreactivity specific for CII was scattered in the extracellular matrix over a wide area of the mesenchymal connective tissue of the fetal tongue on E15, when the lingual epithelium was composed of one or two layers of cuboidal cells. Immunoreactivity became more and more significant in the connective tissue of the lamina propria as morphogenesis of the filiform papillae advanced at birth. In addition, immunoreactivity was widely distributed in the connective tissue around the lingual muscle, as myogenesis in the tongue proceeded. The lingual epithelium was composed of stratified squamous cells, and keratinization of the lingual epithelium increased gradually as morphogenesis of filiform papillae continued during postnatal development. The present observations indicate that expression of $\mathrm{CII}$ might be related to the development of the endomysium and perimysium after myogenesis of the tongue is complete on P0. Rahkonen and Savontaus (2003) reported that $\mathrm{CII}$ is expressed in the epithelial-mesenchymal area of the developing heart and participates in the morphogenesis of cardiac valves and septa.

Thus, CII might also be widely expressed during morphogenesis of connective-tissue components after myogenesis of striated muscle. Some common mechanism might be involved in both phenomena. However, in the present study, we failed to define the stages at which the expression of $\mathrm{CII}$ begins and when it ends because the period during which animals were collected began too long after conception and ended too soon after birth (Asami et al., 2008).

We also examined, in semi-ultrathin sections of epoxy resin-embedded samples, the distribution of immunostained CIII, using images obtained in transmission mode, after toluidine blue staining, by LSM, during the morphogenesis of the filiform papillae, the keratinization of the lingual epithelium and the myogenesis of the tongue (Fig. 7). 

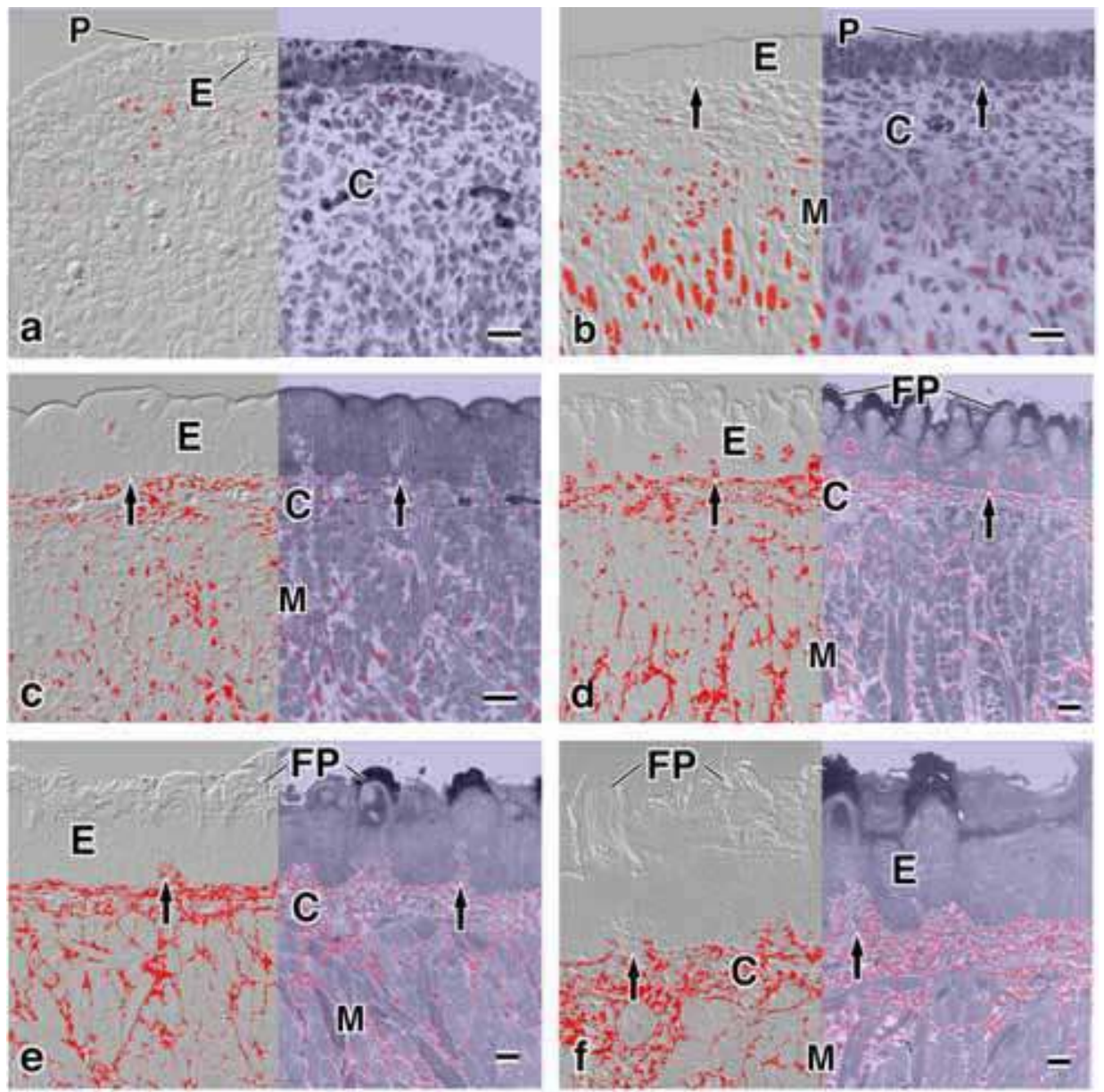

Fig. 6. Combinations of laser-scanning micrographs that show the localization of immunoreactive type $\Pi$ collagen (Alexa Fluor 488; red) and DIC images (left half of each micrograph) or images obtained by LSM in the transmission mode (right half of each micrograph) that show the histology and cellular morphology of semi-ultrathin sections of the lingual body.
(a) Frontal section from a fetus on E15;
(b) sagittal section from a fetus on E17;
(c) sagittal section from a fetus on E19;
(d) sagittal section from a juvenile on $\mathrm{P} 0$;
(e) sagittal section from a juvenile on P7; and
(f) frontal section from a juvenile on P14.

E, Dorsal lingual epithelium; P, periderm; C, connective tissue; M, muscle; FP, filiform papillae; and arrow, connective tissue papillae. Bars $=10 \mu \mathrm{m}$. 

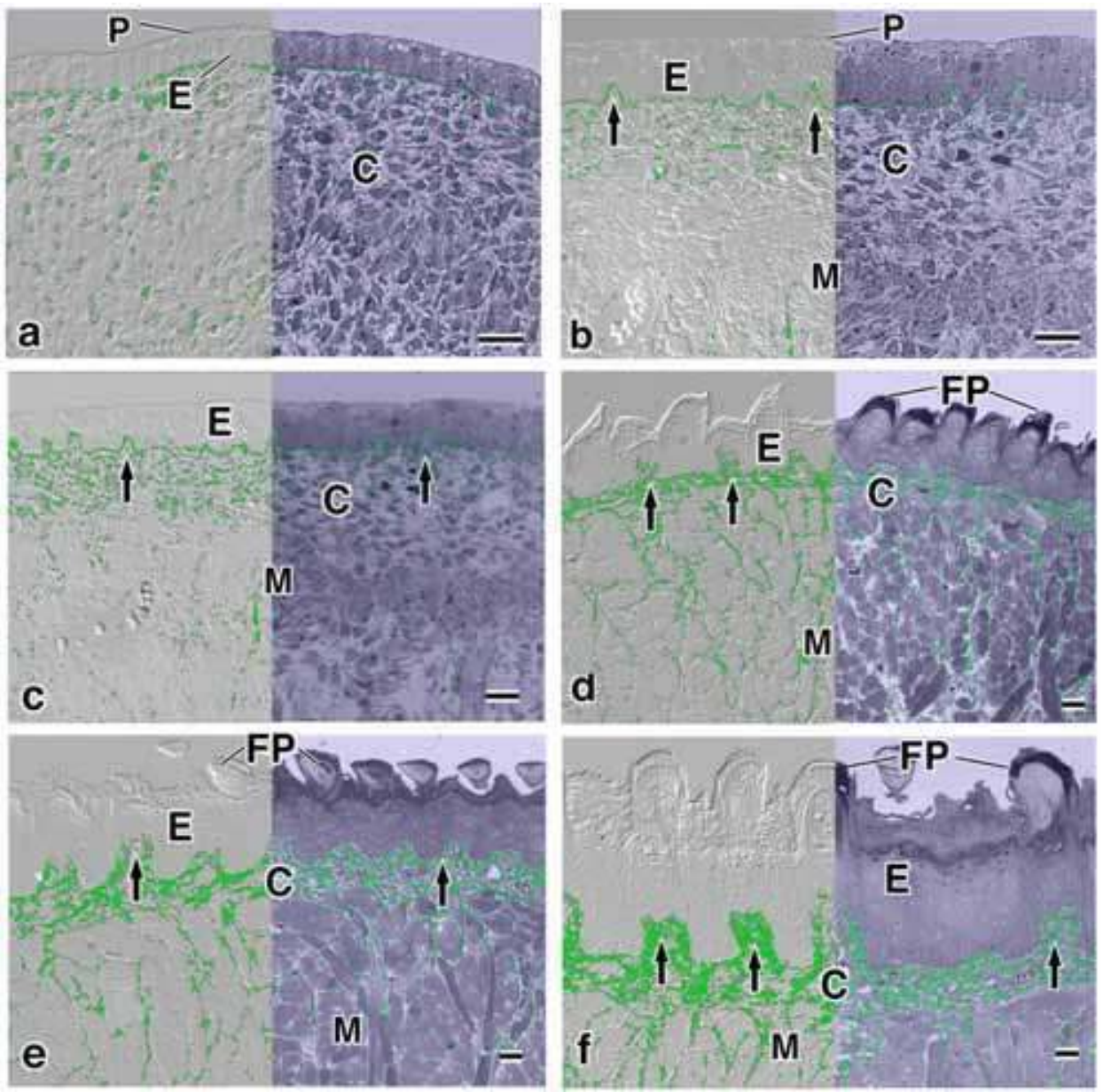

Fig. 7. Combinations of laser-scanning micrographs that show the localization of immunoreactive type II collagen (Alexa Fluor 633; green) and DIC images (left half of each micrograph) or images obtained by LSM in the transmission mode (right half of each micrograph) that show the histology and cellular morphology of semi-ultrathin sections of the lingual body.
(a) Frontal section from a fetus on E15;
(b) sagittal section from a fetus on E17;
(c) sagittal section from a fetus on E19;
(d) sagittal section from a juvenile on $\mathrm{P} 0$;
(e) sagittal section from a juvenile on P7; and
(f) frontal section from a juvenile on P14.

E, Dorsal lingual epithelium; P, periderm; C, connective tissue; M, muscle; FP, filiform papillae; and arrow, connective tissue papillae. Bars $=10 \mu \mathrm{m}$. 
Immunoreactivity specific for CIII was distributed widely in the mesenchymal connective tissue in fetuses on E15, at which time the lingual epithelium was composed of one or two layers of cuboidal cells and the lingual muscle was barely recognizable. Immunoreactivity specific for CIII was clearly detected on the lamina propria in fetuses on E17 and on E19, and it was relatively distinct just beneath the lingual epithelium. Immunoreactivity specific for CIII was sparsely distributed on the connective tissue around the developing lingual muscle. In fetuses on E19, the epithelium became clearly stratified and squamous. At postnatal stages from birth to P14, keratinization of the lingual epithelium advanced gradually with the development of filiform papillae. In newborns on P0, myogenesis of the tongue was almost complete. The intensity of the fluorescence due to immunoreactivity specific for CIII at postnatal stages was almost same as that on E19. However, fluorescence just beneath the lingual epithelium had disappeared on P14. The immunoreactivity around the fully mature muscle was relatively distinct from P0 to P14. Thus, CIII appeared in conjunction with the morphogenesis of filiform papillae and the keratinization of the lingual epithelium, as well as in the connective tissue that surrounded the lingual muscle during myogenesis of the rat tongue (Iwasaki et al., 2008).

\subsection{Localization of immunofluorescence specific for $\mathrm{Cll}$ and $\mathrm{CIII}$ in the lingual mucosa during morphogenesis of gustatory papillae}

Immunoreactivity specific for CII was recognized first in the mesenchymal connective tissue just beneath the circumvallate papilla placode in fetuses on E13. At this stage, most of the lingual epithelium was pseudostratified epithelium composed of one or two layers of cuboidal cells. However, the epithelium of the circumvallate papilla placode was composed of several layers of cuboidal cells. Immunoreactivity specific for CII was detected mainly on the lamina propria just beneath the lingual epithelium of the rudiment of the circumvallate papilla in fetuses on E15 and on E17, and slight immunostaining was detected on the lamina propria around the rudiment. In fetuses on E19, immunoreactivity specific for CII was widely and densely distributed on the connective tissue around the developing circumvallate papillae and on the connective tissue that surrounded the lingual muscle. Immunoreactivity specific for CII was sparsely distributed on the lamina propria of the central bulge. After birth, morphogenesis of the circumvallate papillae advanced gradually with the increase in size of the tongue. Immunoreactivity specific for CII was distinctively distributed in the lamina propria around circumvallate papilla, in the central bulge, and in the connective tissue that surrounded the lingual muscle. The examination of specimens by LSM, in transmission mode, after staining with toluidine blue, revealed details of the histology and cell morphology of the dorsal mucosa more effectively than examination of similar DIC images. The circumvallate papillary placode could be seen on the dorsal surface of the lingual root of fetuses on E13. The rudiment of the circumvallate papilla developed gradually in fetuses, and morphogenesis of the circumvallate papilla progressed significantly at postnatal stages. Except at early stages, CII appeared not only in the connective tissue of the lamina propria but also in the connective tissue papillae during the morphogenesis of the rat tongue. In addition, $\mathrm{CII}$ appeared in the connective tissue that surrounded the lingual muscle and its presence seemed to be related to the development of the endomysium and perimysium after completion of the myogenesis of the tongue (Figs. 8 and 9). 

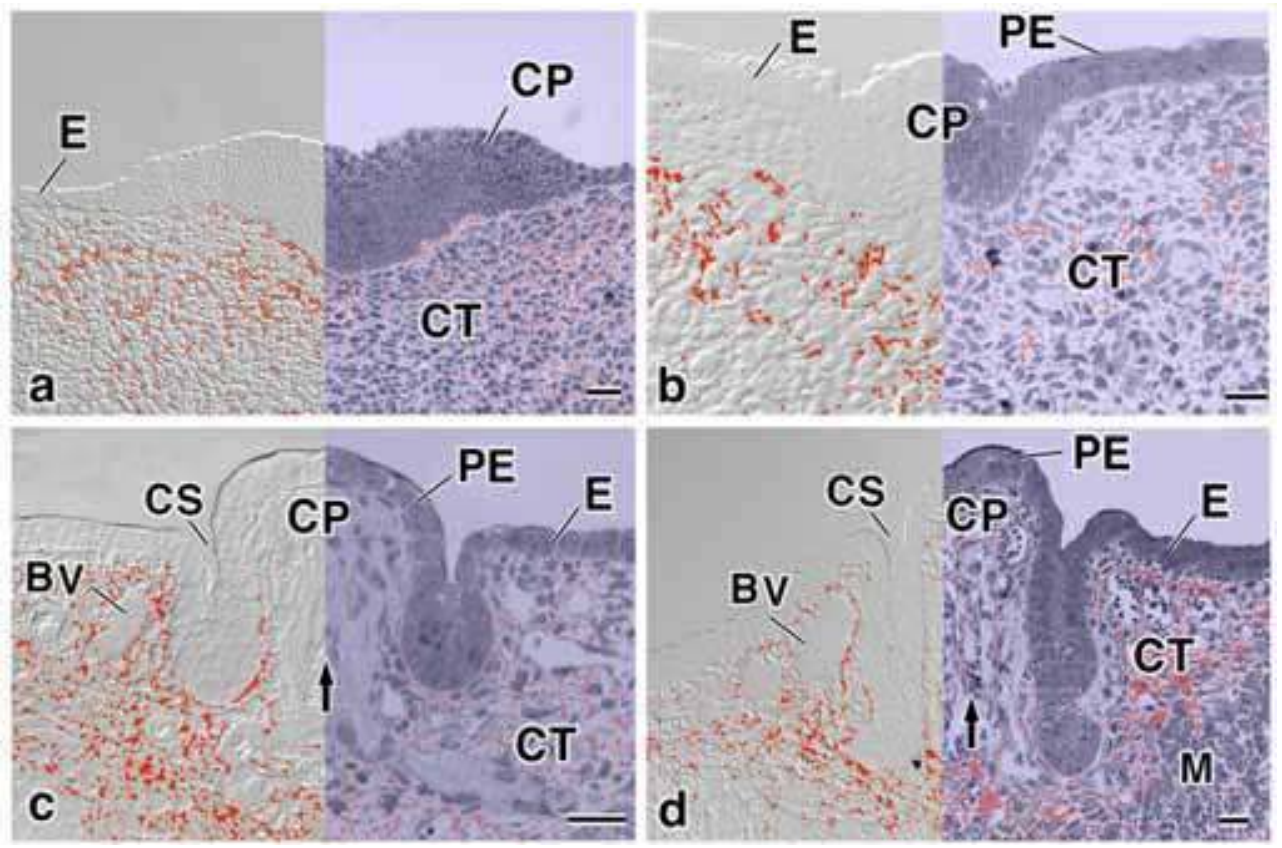

Fig. 8. Combinations of laser-scanning micrographs that show the localization (Alexa Fluor 488 ; red) of immunoreactive type $\Pi$ collagen and DIC images (left half of each micrograph) or images obtained by LSM in the transmission mode (right half of each micrograph) that show the histology and morphology of cells in semi-ultrathin sections of the developing circumvallate papillary area in fetal rats.

(a) Frontal section from a fetus on E13;

(b) frontal section from a fetus on E15;

(c) frontal section from a fetus on E17; and

(d) frontal section from a fetus on E19.

E, Dorsal lingual epithelium; PE, periderm; CT, connective tissue; M, muscle; CP, circumvallate papillary placode or the rudiment of the circumvallate papilla; CS, circular sulcus; BV, blood vessel; and arrow, connective-tissue papilla of the central papilla. Bars = $20 \mu \mathrm{m}$.

In an effort to identify a possible role for $\mathrm{CII}$ in the morphogenesis of circumvallate papillae on the surface of the rat tongue, we examined its appearance by fluorescent immunostaining, in conjunction with DIC images and images obtained, after staining with toluidine blue, by LSM in the transmission mode. We analyzed semi-ultrathin sections of epoxy resin-embedded samples of the lingual mucosa of embryonic and juvenile rats, from E13 to P21. Immunoreactivity specific for CIII was recognized first in the mesenchymal connective tissue just beneath the circumvallate papillary placode on E13. At this stage, most of the lingual epithelium with the exception of the circumvallate papilla placode was pseudostratified epithelium that was composed of one or two layers of cuboidal cells. 

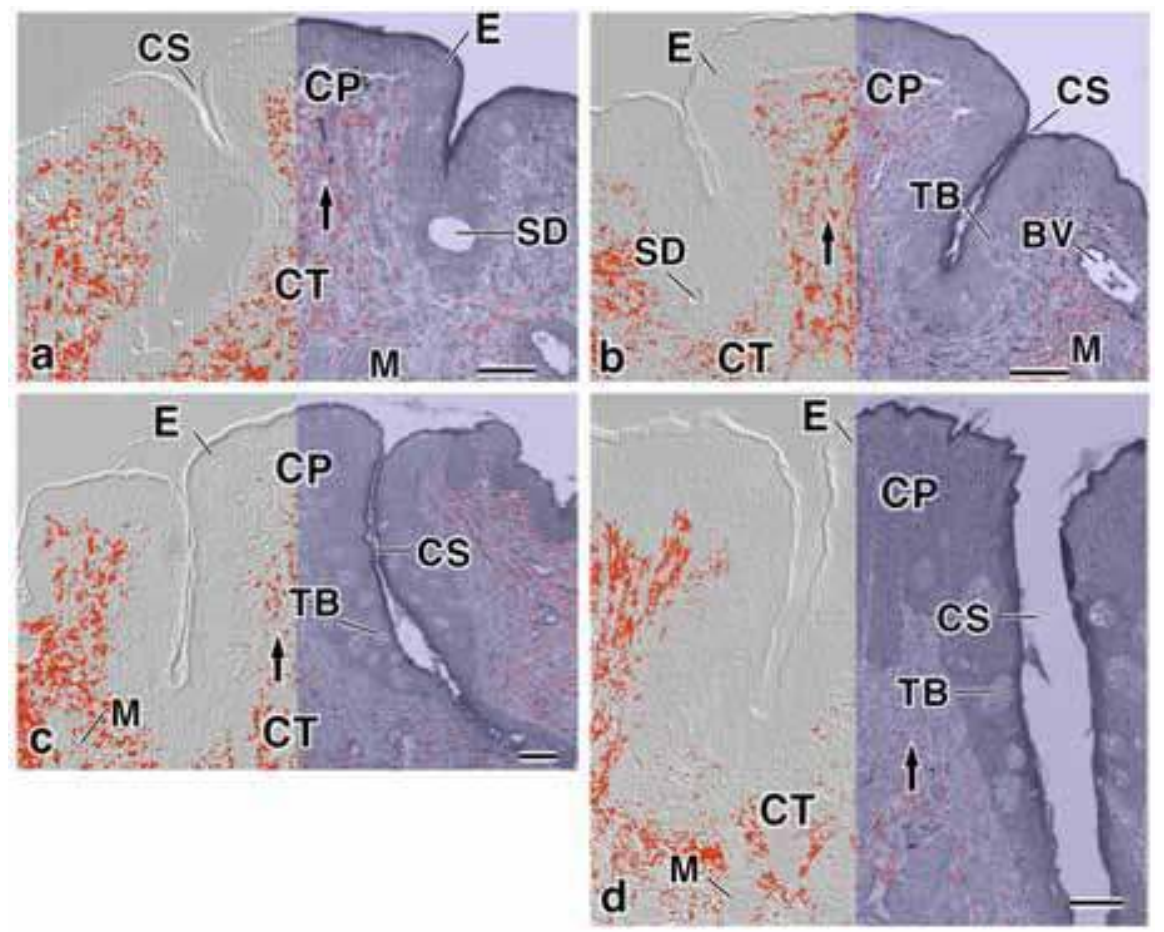

Fig. 9. Combinations of laser-scanning micrographs that show the localization (Alexa Fluor 488; red) of immunoreactive type $\Pi$ collagen and DIC images (left half of each micrograph) or images obtained by LSM in the transmission mode (right half of each micrograph) that show the histology and morphology of cells in semi-ultrathin sections of the developing circumvallate papillary area in juvenile rats.

(a) Frontal section from a fetus on E13;

(b) frontal section from a fetus on E15;

(c) frontal section from a fetus on E17; and

(d) frontal section from a fetus on E19.

E, Dorsal lingual epithelium; CT, connective tissue; M, muscle; CP, circumvallate papilla; CS, circular sulcus; SD, secretory duct of the Ebner's gland; TB, taste buds; and arrow, connective-tissue papilla of the central papilla. Bars $=50 \mu \mathrm{m}$.

However, the epithelium of the circumvallate papillary placode was composed of several layers of cuboidal cells. Immunoreactivity specific for CIII was detected mainly on the lamina propria just beneath the lingual epithelium of the rudiment of the circumvallate papilla and the developing circumvallate papilla in fetuses on E15 and on E17, and slight immunostaining was detected on the lamina propria around the rudiment. In fetuses on E19, immunoreactivity specific for CIII was widely and densely distributed on the connective tissue around the developing circumvallate papillae and, also, on the connective tissue that surrounded the lingual muscle. How ever, the immunoreactivity specific for CIII 

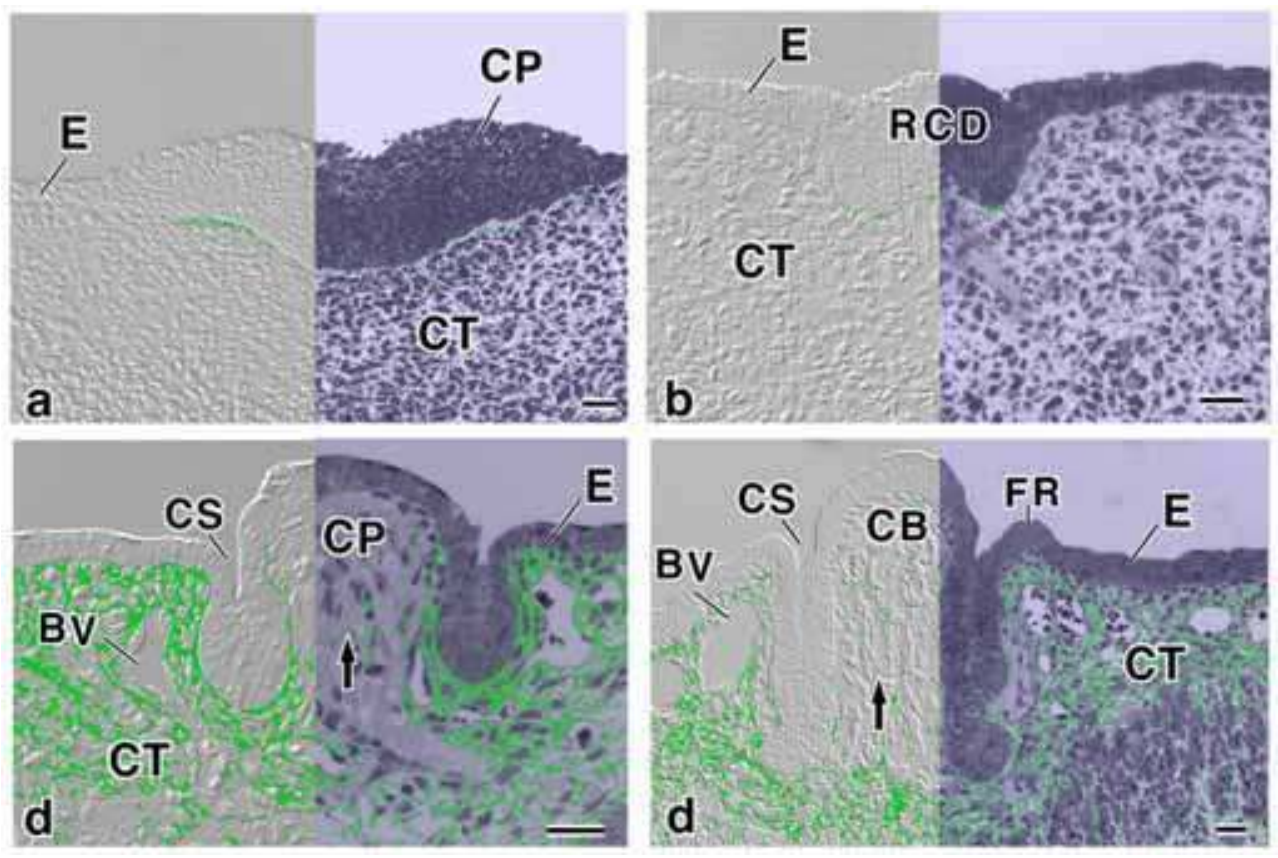

Fig. 10. Combinations of laser-scanning micrographs that show the localization (Alexa Fluor 633; green) of immunoreactive type III collagen and DIC images (left half of each micrograph) or images obtained by LSM in the transmission mode (right half of each micrograph) that show the histology and morphology of cells in semi-ultrathin sections of the developing circumvallate papillary area in fetal rats.

(a) Frontal section from a fetus on E13;

(b) frontal section from a fetus on E15;

(c) frontal section from a fetus on E17; and

(d) frontal section from a fetus on E19.

E, Dorsal lingual epithelium; PE, periderm; CT, connective tissue; M, muscle; CP, circumvallate papillary placode or the rudiment of the circumvallate papilla; CS, circular sulcus; BV, blood vessel; and arrow, connective-tissue papilla of the central papilla. Bars = $10 \mu \mathrm{m}$.

was sparsely distributed on the lamina propria of each central papillar structure. After birth, from P0 to P14, morphogenesis of the circumvallate papillae advanced gradually as the total volume of the tongue increased. At these postnatal stages, the intensity of the fluorescence due to immunoreactivity specific for CIII was distinctively distributed on the lamina propria around each circumvallate papilla, on each central bulge, and on the connective tissue that surrounded the lingual muscle. However, immunofluorescence was less distinct on the connective tissue that surrounded the lingual muscle. Thus, CIII appeared in conjunction with the morphogenesis of the circumvallate papillae, as well as in the connective tissue that surrounded the lingual muscle during myogenesis of the rat tongue (Figs. 10 and 11). 

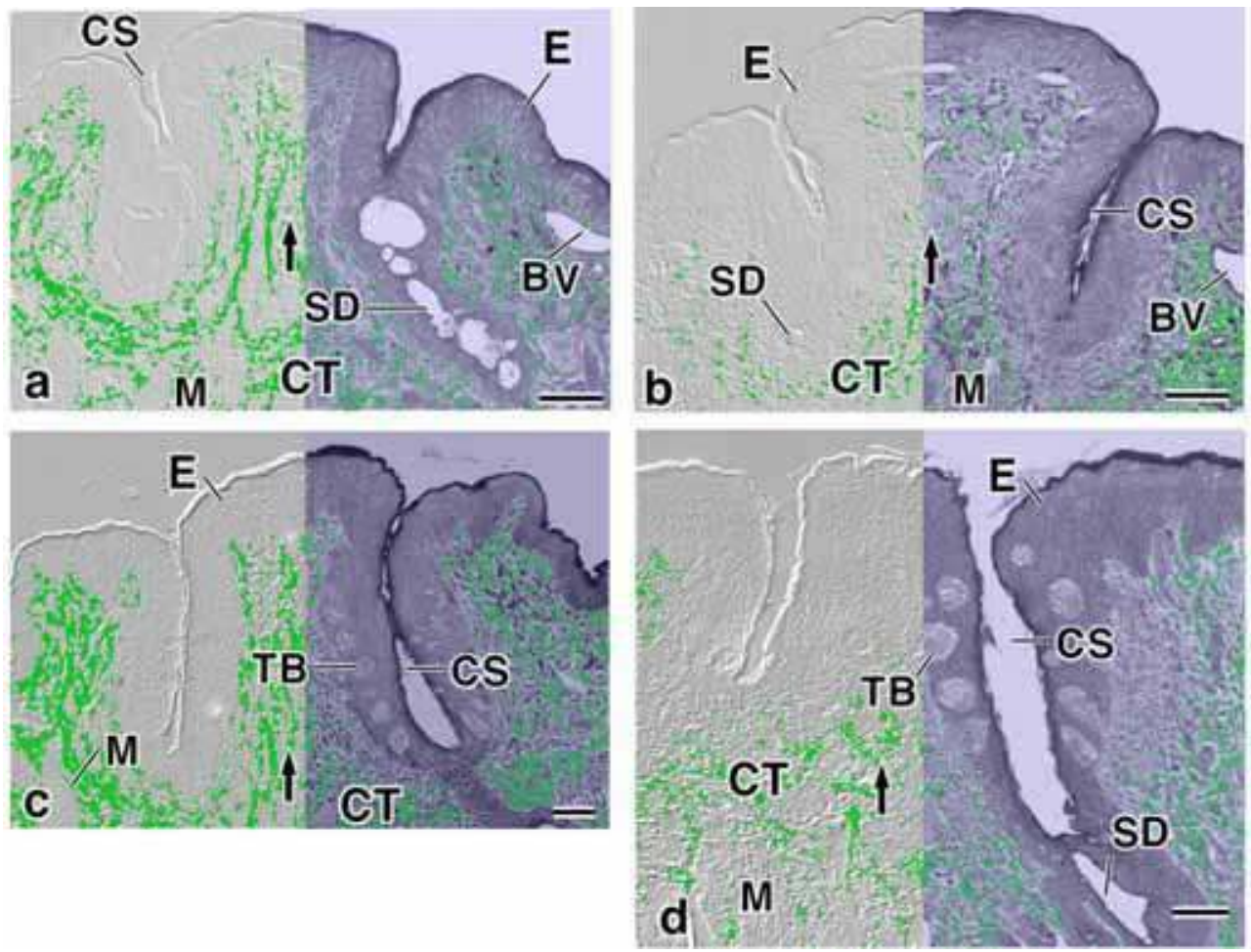

Fig. 11. Combinations of laser-scanning micrographs that show the localization (Alexa Fluor 633; green) of immunoreactive type III collagen and DIC images (left half of each micrograph) or images obtained by LSM in the transmission mode (right half of each micrograph) that show the histology and morphology of cells in semi-ultrathin sections of the developing circumvallate papillary area in juvenile rats.

(a) Frontal section from a fetus on E13;

(b) frontal section from a fetus on E15;

(c) frontal section from a fetus on E17; and

(d) frontal section from a fetus on E19.

E, Dorsal lingual epithelium; CT, connective tissue; M, muscle; CP, circumvallate papilla; CS, circular sulcus; SD, secretory duct of the Ebner's gland; TB, taste buds; and arrow, connective-tissue papilla of the central papilla. Bars $=50 \mu \mathrm{m}$.

\subsection{Analysis of methodology}

For the examination of sections by LSM, we found that microw ave heating of specimens just before immunofluorescence staining was useful for the retrieval of antigens in epoxy resinembedded specimens, even though this treatment had originally been developed for the retrieval of antigens in formalin-fixed, paraffin-embedded specimens. In our previous and present attempts to clarify the localization of immunoreactivity in tissues and cells, we used only a combination of immunofluorescence staining of semi-ultrathin sections and 
corresponding DIC images obtained by LSM. Using this technique, we were easily able to detect and localize immunofluorescence in the tongues of rat fetuses and juveniles at embryonic and postnatal stages (Iwasaki et al., 2003, 2006a, b, 2007a, b). In some of our previous studies, by contrast, we used LSM in the transmission mode to examine the same specimens as those in which we had monitored fluorescence in an effort to reveal histological and cell-morphological features more distinctly than those revealed in DIC images. By combining immunofluorescence images and the corresponding images obtained by LSM in the transmission mode, we were able to define the histological localization of various antigens more clearly than when we combined immunofluorescence images and the corresponding DIC images. Our method, using both light microscopy and confocal laserscanning microscopy, should be applicable to various kinds of tissue and cell of which only very small amounts are available.

\section{Conclusion}

We have developed a technique, using a combination of immunofluorescence staining of semi-ultrathin sections of epoxy resin-embedded samples and the DIC images and images in transmission mode obtained by LSM, that provides detailed information about the immunolocalization of antigens and histological and cellular structures. To demonstrate the effectiveness of our method, we examined the immunofluorescence of immunostained K13 and K14 and that of immunostained CII and CIII and the corresponding DIC and transmission images during the morphogenesis of filiform papillae on the lingual epithelium of rat fetuses and juveniles. We demonstrated that our newly developed technique for localization of pairs of antigens should be useful for investigations of very small specimens, such as fetal tissues and organs.

\section{References}

Aoyagi, H., Asami, T., Yoshizawa, H., Wanichanon, C. \& Iwasaki, S. (2008) Newly developed technique for dual localization of keratins 13 and 14 by fluorescence immunohistochemistry. Acta Histochemica 110(No. 4): 324-332.

Asami, T., Aoyagi, H, Yoshizawa, H., Wanichanon, C. \& Iwasaki, S. (2008) Immunohistochemical expression of type II collagen in the lingual mucosa of rats during the morphogenesis of the tongue. Archives of Oral Biology 53(No. 7): 622-628.

Haraguchi, C.M. \& Yokota, S. (2002) Immunofluorescence technique for 100-nm-thick semithin sections of epon-embedded tissues. Histochemistry and Cell Biology 117(No. 1): 81-85.

Iwasaki, S., Yoshizawa, H. \& Kawahara, I. (1997) Study by scanning electron microscopy of the morphogenesis of three types of lingual papilla in the rat. The Anatomical Record 247(No. 4): 528-541.

Iwasaki, S., Yoshizawa, H. \& Kawahara, I. (1999) Ultrastructural study of the relationship between the morphogenesis of filiform papillae and keratinization of the lingual epithelium in the rat. eburnal of Anatomy 195(No. 1): 27-38.

Iwasaki, S., Aoyagi, H. \& Yoshizawa, H. (2003) Immunohistochemical detection of the expression of keratin 14 in the lingual epithelium of rats during the morphogenesis of filiform papillae. Archives of Oral Biology 48(No. 8): 605-613. 
Iwasaki, S., Yoshizawa, H. \& Aoyagi, H. (2006a) Immunohistochemical expression of keratins 13 and 14 in the lingual epithelium of rats during the morphogenesis of filiform papillae. Archives of Oral Biology 51(No. 5): 416-426.

Iw asaki, S., Aoyagi, H. \& Asami, T. (2006b) Expression of keratin 18 in the periderm cells of the lingual epithelium of fetal rats: visualization by fluorescence immunohistochemistry and differential interference contrast microscopy. Odontology 94(No. 1): 64-68.

Iwasaki, S. \& Aoyagi, H. (2007a) Expression of keratin 14 in the basal cells of the lingual epithelium of mice during the morphogenesis of filiform papillae: visualization by fluorescent immunostaining and confocal laser-scanning microscopy in the transmission mode. Odontology 95(No. 1): 61-65.

Iwasaki, S., Aoyagi, H. \& Yoshizawa, H. (2007b) Immunohistochemical detection of epidermal growth factor and epidermal growth factor receptor in the lingual mucosa of rats during the morphogenesis of filiform papillae. Acta Histochemica 109(No. 1): 37-44.

Iwasaki, S., Asami, T., Wanichanon, C., Yoshizawa, H. \& Aoyagi, H. (2008) Immunohistochemical analysis of type III collagen expression in the lingual mucosa of rats during organogenesis of the tongue. Odontology 96(No. 1): 12-20.

Iwasaki, S., Aoyagi, H. \& Yoshizawa, H. (2011a) Localization of keratins 13 and 14 in the lingual mucosa of rats during the morphogenesis of circumvallate papillae. Acta Histochemica 113: in press.

Iwasaki, S., Aoyagi, H. \& Yoshizawa, H. (2011b) Localization of type II collagen in the lingual mucosa of rats during the morphogenesis of circumvallate papillae. Acta Zoologica 92 (No. 1): 67-74.

Litwin, J.A., Yokota, S., Hashimoto, T. \& Fahimi, H.D. (1984) Light microscopic immunocytochemical demonstration of peroxisomal enzymes in epon sections. Histochemistry 81(No. 1): 15-22.

Mayor, H.D., Hampton, J.C. \& Rosario, B. (1961) A simple method for removing the resin from epoxy-embedded tissue. eburnal of Cell Biology 9(No. 4): 909-910.

Rahkonen, O., Savontaus, M. (2003) Expression pattern of cartilage collagens and Sox9 during mouse heart development. Histochemistry and Cell Biology 120(No. 2): 103110 .

Shi S.-R., Key M.E. \& Karla K.L. (1991) Antigen retrieval in formalin-fixed, paraffinembedded tissues: an enhanced method for immunohistochemical staining based on microwave heating of tissue sections. eburnal of Histochemistry and Cytochemistry 39(No. 6): 741-748. 


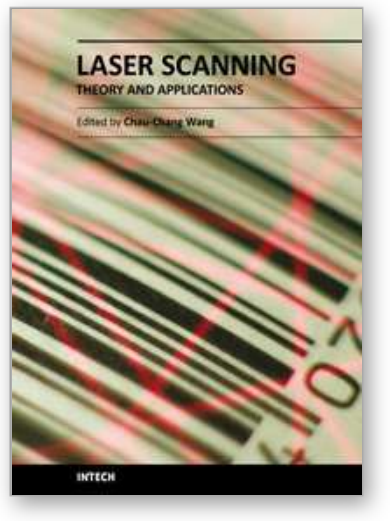

\author{
Laser Scanning, Theory and Applications \\ Edited by Prof. Chau-Chang Wang
}

ISBN 978-953-307-205-0

Hard cover, 566 pages

Publisher InTech

Published online 26, April, 2011

Published in print edition April, 2011

Ever since the invention of laser by Schawlow and Townes in 1958, various innovative ideas of laser-based applications emerge very year. At the same time, scientists and engineers keep on improving laser's power density, size, and cost which patch up the gap between theories and implementations. More importantly, our everyday life is changed and influenced by lasers even though we may not be fully aware of its existence. For example, it is there in cross-continent phone calls, price tag scanning in supermarkets, pointers in the classrooms, printers in the offices, accurate metal cutting in machine shops, etc. In this volume, we focus the recent developments related to laser scanning, a very powerful technique used in features detection and measurement. We invited researchers who do fundamental works in laser scanning theories or apply the principles of laser scanning to tackle problems encountered in medicine, geodesic survey, biology and archaeology. Twenty-eight chapters contributed by authors around the world to constitute this comprehensive book.

\title{
How to reference
}

In order to correctly reference this scholarly work, feel free to copy and paste the following:

Shin-ichi Iwasaki and Hidekazu Aoyagi (2011). Fluorescence Immunohistochemistry by Confocal LaserScanning Microscopy for Studies of Semi-Ultrathin Specimens of Epoxy Resin-Embedded Samples, Laser Scanning, Theory and Applications, Prof. Chau-Chang Wang (Ed.), ISBN: 978-953-307-205-0, InTech, Available from: http://www.intechopen.com/books/laser-scanning-theory-and-applications/fluorescenceimmunohistochemistry-by-confocal-laser-scanning-microscopy-for-studies-of-semi-ultrathi

\section{INTECH}

open science | open minds

\section{InTech Europe}

University Campus STeP Ri

Slavka Krautzeka 83/A

51000 Rijeka, Croatia

Phone: +385 (51) 770447

Fax: +385 (51) 686166

www.intechopen.com

\section{InTech China}

Unit 405, Office Block, Hotel Equatorial Shanghai

No.65, Yan An Road (West), Shanghai, 200040, China 中国上海市延安西路65号上海国际贵都大饭店办公楼 405 单元

Phone: $+86-21-62489820$

Fax: $+86-21-62489821$ 
(C) 2011 The Author(s). Licensee IntechOpen. This chapter is distributed under the terms of the Creative Commons Attribution-NonCommercialShareAlike-3.0 License, which permits use, distribution and reproduction for non-commercial purposes, provided the original is properly cited and derivative works building on this content are distributed under the same license. 